\title{
Does an Interactive Health Promotion Website Facilitate Workplace Peer-to-Peer Substance Abuse Prevention?
}

\author{
Deborah M. Galvin ${ }^{1}$, Rebecca S. Spicer ${ }^{2}$, Les R. Becker ${ }^{2}$, Ted R. Miller ${ }^{2}$, Dexter M. Taylor ${ }^{2}$, and \\ Julie A. Sabol ${ }^{3}$ \\ ${ }^{1}$ Substance Abuse and Mental Health Services Administration, Center for Substance \\ Abuse Prevention \\ ${ }^{2}$ Pacific Institute for Research and Evaluation \\ ${ }^{3}$ ORC Macro
}

\begin{abstract}
Operation RedBlock, a substance abuse prevention and early intervention program at Amtrak, implemented an interactive health promotion website (On The Right Track, OTRT) for its volunteers, other employees and their families. OTRT was customized from the Substance Abuse and Mental Health Services Administration (SAMHSA) -sponsored GetFit@SAMHSA.GOV website and implemented with the purpose of facilitating the peer-to-peer substance abuse prevention efforts of Operation RedBlock volunteers. SAMHSA's GetFit website combines broad health and wellness messages with current substance abuse prevention resources. The OTRT customization adds Amtrak relevant and specific content concerning substance abuse prevention resources and treatment options, drug and alcohol use policies, health care coverage, support group meeting locations and dates, and local Operation RedBlock and Employee Assistance Program contact information. Using a retrospective pretest-posttest design this study evaluates whether and how OTRT facilitated peer-to-peer efforts in substance abuse prevention and early intervention. The evaluation revealed that the website significantly improved access to information and resources that helped Operation RedBlock volunteers' in their peer-to-peer efforts. Volunteers valued the ready availability of reliable information, the confidential nature, and the ease of use of OTRT. Facilitated access to information and resources may help reduce substance abuse among employees at high risk.
\end{abstract}

(C) 2012 Californian Journal of Health Promotion. All rights reserved.

Keywords: Interactive Health Communication, evaluation, peers, substance abuse, workplace

\section{Introduction}

Drug and alcohol abuse and addiction is recognized as a serious risk to the health and safety of the user and others (NIAAA, 1997). Alcohol and drug abuse is a particular concern in the workplace. Studies show that alcohol and other drug users are far less productive than nonusers, use three times as many sick days, are more likely to injure themselves or someone else, and are five times more likely to file workers' compensation claims (Normand et al. 1994). Most substance users are employed either full- or part-time (SAMHSA 2009). An analysis of 2008 National Survey on Drug Use and Health (a nationally representative sample of
U.S. households) found that among full-time employed persons aged 18 to 64 years, 8.8 percent reported past month heavy alcohol use, 8.2 percent reported past year alcohol dependence or abuse, 8.2 percent reported past month illicit drug use, and 2.6 percent reported past year illicit drug dependence or abuse (Larson et. al. 2007). Rates for part-time employed persons were slightly higher.

In this digital age, the internet increasingly has been used to access health information and manage health issues, including substance abuse. Interactive health communication (IHC) has shown promise in addressing substance abuse within specific populations, including 
workforces. IHC refers to individuals' use of electronic devices or other forms of communication technology to access or transmit health information, or to receive or provide guidance and support on a health-related issue (Robinson, Patrick, Eng, \& Gustafson, 1998). In $2011,78 \%$ of adults 18 years and over reported using the internet (United States Census Bureau, 2012a). Of these, $55 \%$ reported searching for advice or information about health or health care (United States Census Bureau, 2012b). Consumers, patients, caregivers, and health professionals are increasingly using IHC in both the public and the private sectors.

Several IHCs address substance abuse. Walters, Miller, and Chiauzzi (2005) identified five commercially available alcohol education and intervention programs that target college drinkers. A literature review by Copeland and Martin (2004) concluded that internet-based substance use disorder interventions could be effective for the majority of less severely dependent clients. A free and voluntary six week IHC intervention to promote sensible drinking found reduced dependency, alcohol-related problems and mental health symptoms postintervention (Linke, Murray, Butler, \& Wallace, 2007). Doumas, McKinley, and Book (2009) compared the efficacy of a Web-based intervention that included normative feedback on individual and peer drinking versus a Webbased education program without feedback among randomly assigned college students who had received alcohol-related sanctions. Students randomized to the Web-based intervention with feedback had significantly greater reductions in weekly drinking quantity, peak alcohol consumption, and frequency of drinking to intoxication than students without feedback.

These studies assessed the impact of IHCs on patients as the end-users. In the dominant report in this field, the Science Panel on Interactive Communication and Health (1999) recommended that developers of IHC applications strive to enhance the capacity of stakeholders to develop and use the technology. Documented efforts include IHCs used to assist health professionals in screening and treating their patients (Noah et al., 2004; Casebeer et al., 2003). However, the literature lacks studies of the role of IHCs in assisting peers and families in the treatment, management, or prevention of health-related problems among their peers and family members.

The GetFit@SAMHSA.GOV website, developed from a prototype website designed by Matano, Futa, Wanat, Mussman, and Leung (2000), addresses employee health and wellness issues including substance abuse and mental health problems that frequently receive less attention than other health issues. Matano et al. (2000) found the website reduced the stigma of seeking assistance for substance abuse problems and mental health issues. In all, 145 employees with low to moderate risk for alcohol problems were given access to the website and its feedback on stress levels and coping strategies (Matano et al., 2007). Half were randomized to receive additional feedback about their risk for alcohol-related problems. While sample sizes were limited, the researchers found some evidence that the additional feedback on alcohol risks reduced binge drinking. Other findings from the Matano studies included the low cost of operating a health and wellness website and its ability to have far-reaching benefits for employees and their families.

The current study evaluates an IHC website and its use as a tool for employees helping fellow employees at Amtrak, a US passenger railroad company, with substance abuse problems. Historically, workplace characteristics and an occupational drinking culture enabled alcohol use to become an important component of worker lifestyle in the railroad industry. Drinking at work and when on call was so pervasive that in the 1860s and 1870s rail labor organizations served as temperance groups and required sobriety for membership. These programs continue today and, combined with random screening programs that began in 1989, have dramatically reduced workplace alcohol and drug use (Miller et al., 2007). However, the need to address any residual substance abuse and addiction among workers in this safety-sensitive environment persists.

The website, called On the Right Track (OTRT), was custom adapted from the SAMHSA- 
sponsored GetFit@SAMHSA.GOV website to facilitate peer-to-peer substance abuse prevention efforts at Amtrak. The website was implemented with the purpose of enhancing a well-established peer-to-peer substance abuse prevention and early intervention program at Amtrak called Operation RedBlock. This paper first describes the involvement of the unions, employees, management, administration and other stakeholders (all those who might use or be affected by the website) in the development and implementation of the website. Next, the paper examines stakeholder use of OTRT. Finally, using a retrospective pretest-posttest design the study evaluates whether and how OTRT facilitates Operation RedBlock substance abuse prevention efforts. We hypothesize that confidential access to information and resources on substance use and abuse, support group meetings, and treatment options facilitates peer efforts in substance abuse prevention and early intervention with their co-workers.

\section{Methods}

\section{Setting}

The study company, Amtrak, is a national passenger railroad company that employs about 26,000 workers with approximately $80 \%$ union membership. OTRT was developed to facilitate the efforts of a workplace substance abuse prevention and early intervention program, Operation RedBlock. Operation RedBlock is an ongoing peer-to-peer program started in 1987 at Amtrak to address the drinking and drugging culture in the workplace and help fellow employees with substance abuse problems. The program has been credited with improving workplace safety by reducing workplace injuries and costs (Spicer and Miller, 2005; Miller et al., 2007).

Operation RedBlock is a union-management partnership. Central to Operation RedBlock is the network of teams that have been trained to identify employees with substance use problems and help them seek help (Bacharach, Bamberger, \& Sonnenstuhl, 1996). The teams are organized by worksite, each one made up of employee volunteers, including one captain and varying numbers of employee volunteers. All volunteers complete a 1- or 2-day training course to learn how to recognize and intervene with a coworker who has a drinking or drug problem. By 2003, 6,500 employees had received the training and about 2,400 volunteers actively staffed the 152 teams.

\section{Website Adaptation}

OTRT is a customized version of the evidencebased, workplace-oriented GetFit health and wellness website (Galvin, 2003; Matano et al., 2000) targeting substance abuse prevention and early intervention. The website was implemented at Amtrak as a tool to make it easier for Amtrak employees and family members to access content concerning substance abuse prevention and treatment, policies, programs and services, benefits, support groups and contact information. For Operation RedBlock teams, specifically, it is intended to facilitate finding and providing information and resources on substance use and abuse, support group meetings and substance abuse treatment options for peers who need help. The website provides a means to access help and information confidentially and without the stigma attached to help-seeking. Confidentiality is important to Operation RedBlock and Amtrak workers who face severe penalties, including termination, if it is known the worker used illegal drugs or abuse alcohol. Stakeholders include the unions; Amtrak administration, employees, and management; and Operation RedBlock volunteer members and captains.

The SAMHSA GetFit website combines broad health and wellness messages with substance abuse prevention resources. It offers referral resources on health-related issues such as stress, depression, family issues, illness and disease, nutrition, physical fitness and trauma in addition to substance abuse. Screening tools are also available to help employees identify, understand, and seek help for drug and alcohol problems, in addition to physical health and mental health issues. The information is organized into four sections: At Work, At Play, In the Home, and In the Community. The "At Work" or the "In the Community" sections can be customized. 
In the OTRT adaptation the "At Work" section was customized to meet the needs and culture of Amtrak and support Operation RedBlock efforts. Based on input from senior Operation RedBlock and Employee Assistance Program staff, content was added that included Amtrak polices on workplace substance use, dates and locations of AA and NA meetings, and Operation RedBlock news and contact information. This section also was linked to a workplace glossary, frequently asked questions, employee assistance services, health care and employee treatment options, and other related topics. The website was given a railroad theme and name to make it friendly to railroad workers.

Before and during adaptation, feedback from Operation RedBlock staff was solicited in 4 categories: 1) Confidentiality, anonymity, and comfort; 2) User-friendly options to print, e-mail and save pages; 3) Navigation of the website; and 4) Links and pop-up screens. This feedback was then used to finalize the content of OTRT.

1) Confidentiality, Anonymity, and Comfort. During site design, senior Operation RedBlock staff stressed the importance of allaying employees' concerns of breach of confidentiality and anonymity as they seek credible information and resources on substance abuse and mental health issues. These features, critical to all who use or tailor GetFit, were a cornerstone of its design from the outset. To ensure confidentiality, employees can access all website information, articles, self-tests, and links without entering their names or any other personal identifiers. Privacy and disclaimer statements throughout the website stress assurances of employee anonymity. These design features are intended to minimize employees' discomfort when seeking information and assuage concerns of potential stigmatization if their interest in these topics were to become known to coworkers and managers.

2) User-Friendly Options to Print, E-mail, and Save Any Page. The team captains stressed the importance of responding immediately and appropriately with information and resources from the website when an employee comes to them for help. They valued the ability to distribute the information either on hard copy or as an electronic file through email.

3) Navigation of website. Initially, it was unclear if a site map would be a valuable website tool for this audience. Discussions held during the regional meetings suggested that many viewed a site map as the fastest and easiest way to understand Web content. As a result, a comprehensive site map was included along with section headers and concise summaries of the information in each section.

4) Links and Popup Screens. Participants commented that a user could easily but unintentionally leave the site when pursuing links to other information. This might frustrate users seeking multiple pieces of information. As this is a well-known problem of many websites, GetFit had been technically redesigned to reduce "searching" time by hard-coding data within the site. As updates to the newest health information from federal sources continue the hard coding lags in the process. Thus, as GetFit is updated, there are different levels of "wait time" on various health, wellness, and safety information.

\section{Website Implementation}

The OTRT website was made available beginning July 2002 and pilot tested among Operation RedBlock attendees at the six Operation RedBlock quarterly divisional meetings held in August and September, 2002. Between 20 and 30 Amtrak employees attended these meetings which included national Operation RedBlock staff, team captains, union leaders and team volunteers. The attendees were given a 1-hour introduction and training in the use of the site. After the training, a one-hour assessment of the attendees' impressions of the website was conducted using nominal group technique (Delbecq, Van de Ven, \& Gustafson, 1975).

Nominal group technique is a method used to facilitate consensus among members of a small group through a series of brief, structured, question-and-answer periods led by a moderator. In this study the process began with the presentation of several questions regarding 
impressions of OTRT. For each question group participants first responded individually and then discussed the responses as a group. Each participant was then asked to list and rank the five 'best' responses to each question. Scores were given to the various responses depending on how often and where each participants ranked that particular response. Total scores were then tallied within each question and responses with the highest scores were considered the responses with the greatest agreement.

\section{Evaluation}

This study used a retrospective pretest-posttest design (Pratt, McGuigan, \& Katzev, 2001) to evaluate the website's ability to facilitate Operation RedBlock team volunteers' efforts to prevent, identify, and intervene early in their peers' problem drug and alcohol use.

Data collection: The evaluation used qualitative data on information accessed and usefulness of the website in addition to quantitative data on website use.

Qualitative data on use and usefulness were collected using a questionnaire that asked a series of questions with separate responses for the periods pre- and post-OTRT implementation. The questionnaire was administered one year and three months post-implementation. Tables $1 \mathrm{~A}$ and $1 \mathrm{~B}$ display the questions posed. The questionnaire was developed with feedback from Operation RedBlock, however it was not validated.

Quantitative data on OTRT page and document views, hits, and unique and repeat visitors were supplied by SAMHSA between July 2002 and June 2003. Counts of hits tend to be inflated because a hit occurs when a user goes to any page within the website and downloads images, text, documents, links, and so on. Thus, even when only one page is viewed, multiple hits may result. Confidentiality guarantees precluded collection of more precise data on the identities of users accessing the website.

\section{Study Sample}

The nominal group technique was conducted with the attendees of the six divisional quarterly
Operation RedBlock meetings in fall, 2002 at the same time. The questionnaire was administered to attendees of the Annual Operation RedBlock conference in October, 2003. Attendees of the annual conferences come from all six of Amtrak's operational regions. Attendees use paid leave and company-funded transportation to attend, thus ensuring participation from all Operation RedBlock regions. About 350 people participate, including Operation RedBlock captains, team volunteers, and Amtrak corporate managers. This group includes nearly all team captains and a subsection of Operation RedBlock team volunteers (on average 3 volunteers per team).

Analysis: A retrospective pretest-posttest design (Pratt, McGuigan, \& Katzev, 2001) was used to measure the ability of the website to facilitate Operation RedBlock efforts in prevention and early intervention in drug and alcohol problems among co-workers. This evaluation design is distinguished from the traditional pretestposttest by its timing relative to the intervention. The retrospective pretest-posttest is administered post-intervention, asking individuals to recall their behavior both prior to and after the intervention. Retrospective pretest-posttest designs lend themselves nicely to withinsubjects analysis. Given the ordinal nature of the survey questions, we used the Wilcoxon Signed Ranks Test for related samples (Siegel \& Castellan Jr., 1988). This test examines the null hypothesis that the median change in score between the pre- and post-scores is different than zero. Tabular analyses of responses to each question were prepared and statistical analyses were conducted using SAS Version 8 (SAS Institute Inc., 1999). To control the experimentwide error rate, we used the Bonferroni (1935, 1936) correction. The level of significance for the 13 multiple comparisons was determined by the calculation ' $=/ \mathrm{k}$, setting $\mathrm{p}<.003$ as the level of significance for the 13 tests conducted.

\section{Results}

\section{Web Trends Data}

Figure 1 displays website usage from July 2002 through June 2003. The plot of "total web hits" is scaled to the second y-axis. The peaks in 
August and October 2002 for document views and total hits correspond to the July, 2002, implementation and subsequent annual conference. Total hit levels declined dramatically after the Operation RedBlock 2002 Annual Meeting. They bottomed out in March 2003, then recovered and stabilized. Although Web hits were unchanged in January and February 2003, document views rose $27.9 \%$ before leveling out for the next several months.

\section{Figure 1}

\section{Web Trends Data for PTRT}

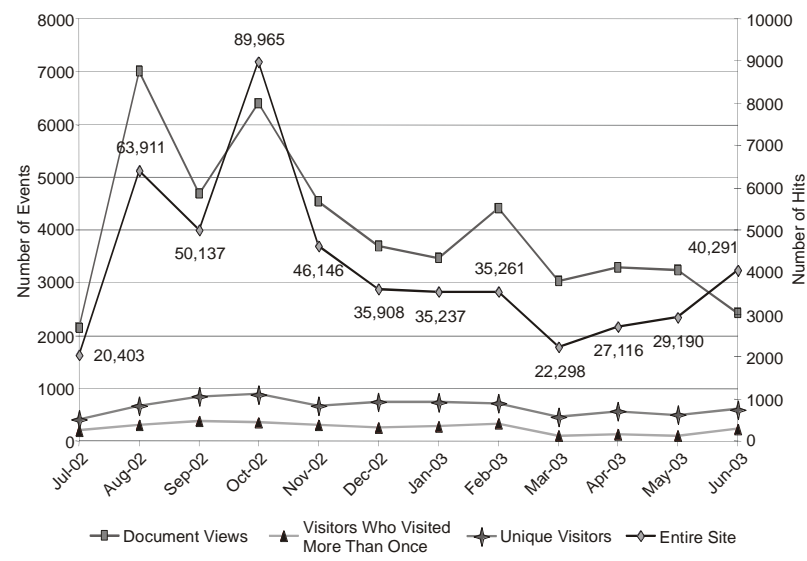

\section{Initial impressions of OTRT}

Based on nominal group technique, Operation RedBlock team volunteers and captains agreed that the anonymous and private nature of the website was the most valuable feature. Group members also cited the usefulness of several internet links on the website (e.g., a link that offered detailed, national information on the time and location of NA and AA meetings). Each division rated the site as a valuable resource for information about substance abuse.

\section{Evaluation}

Of the approximately 350 participants in the 2003 annual Operation RedBlock conference, 219 received a questionnaire. Of these, 161 (73.5\%) returned surveys, though not all questions were completely answered. Complete responses to specific questions for pre- and postcomparisons ranged from 144 to 149 (66\%$68 \%)$.
The large majority of respondents had internet access at work and at home. Of 154 responding regarding internet access, 129 (83.8\%) reported that they had internet access at home, whereas $75(48.7 \%)$ had internet access at work. Only $8.4 \%(13 / 154)$ lacked internet access both at home and at work. This latter statistic is important because it means the likelihood of negative responses simply based on a captain's or team member's lack of internet access is small.

Tables 1A and 1B display the results of the retrospective pretest posttest analysis. In general, Operation RedBlock volunteers and captains reported considerable decreases in the difficulty and/or increases in ease of providing information to coworkers and finding information for themselves after the implementation of OTRT. Statistically significant pretest-posttest differences were revealed for all 13 questions by the initial analysis. Significance at the $99 \%$ confidence level was retained for all but one question (How often did you distribute or post-materials featuring Operation RedBlock slogans?) after applying the Bonferroni correction. A notably large decline was found for reporting that it was very hard or hard to find information that makes the respondent a better RedBlock team member (Table 1A, question \#9); from $37 \%$ pre-OTRT to 9\% post-OTRT. Also the percent reporting that finding information for one's own use (Table 1A, question \#3) declined from $32 \%$ to only $9 \%$ reporting it was very hard or hard. The percentage of respondents who found it easy or very easy to provide new information regarding substance abuse prevention and health to employees or their family members (Table 1A, question \#5) more than doubled (from $27 \%$ to $62 \%$ of respondents). The percentage with easy access to prevention information around the clock more than doubled (from 29\% to 64\%), whereas the percentage who found such access difficult declined from $40 \%$ to $13 \%$ (Table 1A, question \#8). Ease of access to information on NA, AA, and Alanon meeting places and times (Table 1A, question \#7) also improved. 
Table 1A

Questions Probing Difficulty of Providing Service Before and After OTRT

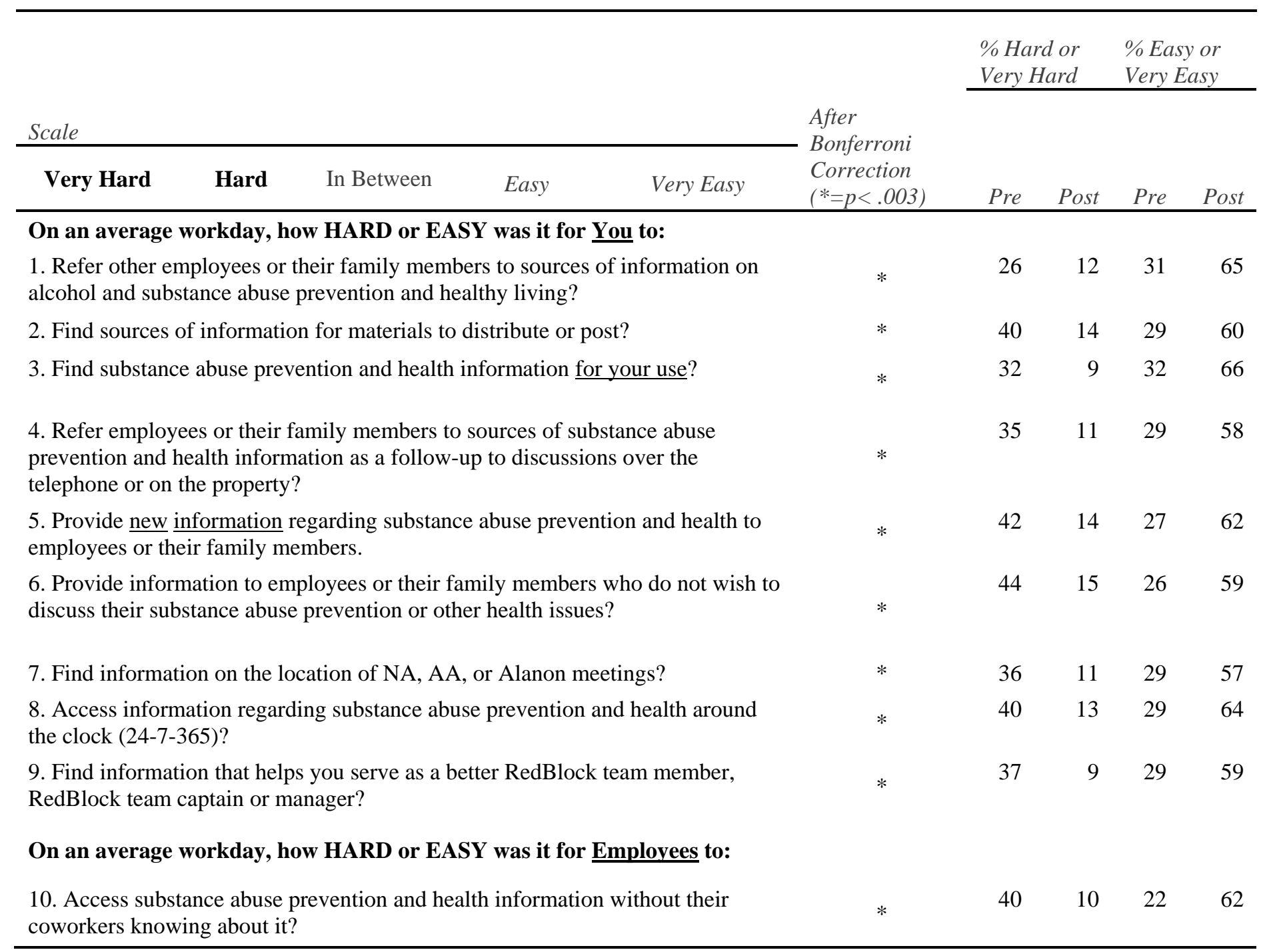


Table 1B

Questions Regarding Frequency of Providing Service

\begin{tabular}{|c|c|c|c|c|c|c|c|}
\hline \multirow{3}{*}{ In an average month, how many times have $\underline{\text { You: }}$} & \multirow{3}{*}{$\begin{array}{c}\text { After } \\
\text { Bonferroni } \\
\text { Correction } \\
(*=p<.003)\end{array}$} & & \multicolumn{5}{|c|}{ Scale (Frequency) } \\
\hline & & Pre & \multirow{2}{*}{0} & \multirow{2}{*}{$1-2$} & \multirow{2}{*}{$3-5$} & \multirow{2}{*}{$6-10$} & \multirow{2}{*}{$>10$} \\
\hline & & Post & & & & & \\
\hline \multirow{2}{*}{$\begin{array}{l}\text { Provided the location of an AA, NA, or Alanon meeting when } \\
\text { asked by a coworker or other employee? }\end{array}$} & \multirow{2}{*}{$*$} & Pre & 47 & 37 & 12 & 1 & 1 \\
\hline & & Post & 36 & 40 & 19 & 3 & 2 \\
\hline \multirow{2}{*}{$\begin{array}{l}\text { Distributed or posted materials featuring Operation RedBlock } \\
\text { slogans? }\end{array}$} & & Pre & 17 & 42 & 22 & 8 & 11 \\
\hline & & Post & 10 & 40 & 24 & 15 & 11 \\
\hline \multirow{2}{*}{$\begin{array}{l}\text { Posted or distributed information not prepared by Operation } \\
\text { RedBlock or provided as handouts (e.g., AA/NA pamphlets, } \\
\text { newspaper/ magazine articles, information from a website). }\end{array}$} & \multirow{2}{*}{$*$} & Pre & 31 & 43 & 12 & 8 & 6 \\
\hline & & Post & 25 & 39 & 19 & 9 & 6 \\
\hline
\end{tabular}

\section{Discussion}

The evaluation suggests that Operation RedBlock volunteer members were aided in their substance abuse prevention and early intervention efforts by OTRT. For every peer task queried in the survey, OTRT substantially increased the ease of doing it every day. Tasks included finding information, posting on bulletin boards to improving their self-understanding of substance abuse and other health content, and referring employees to follow-up information after telephone or in-person conversations. This, in addition to the dramatic gains in easy access to information on NA, AA, and Alanon meetings, may help reduce substance abuse among employees at high risk.

The findings suggest that the site allowed prevention materials to be made available in a manner that respects the confidentiality of the individual. This is important in an environment where confidentiality is valued. OTRT enabled Operation RedBlock volunteers to refer employees discreetly to sources of relevant material in cases where those employees did not choose to confide in the peer helper as to the specific nature of an alcohol- or drug-related issue. Thus, Operation RedBlock, could now reach employees who were previously unreachable, or only haphazardly so, by conventional printed materials.

The large gain reported in access to materials around the clock also was important. Amtrak runs an around-the-clock operation, and employees working onboard trains may be at highest risk and most need advice when away from home but off-duty.

Peer helpers reported that OTRT made it easier to find substance abuse prevention and health promotion information for their own use and to display on bulletin boards. The teams used more materials that were not prepared by Operation RedBlock volunteers as a result, which may be a considerable benefit. Although Operation RedBlock developed materials that are creativeclever, attractive, and customized to the Amtrak worker-materials on the website are likely to be more reliable because they have been vetted by the National Clearinghouse on Drug Abuse Information (NCADI).

This formative evaluation also demonstrates that stakeholder input can be effective in enhancing 
media and technology to maximize its utility to the intended end-users. In this study stakeholders were empowered to offer input not only on content, but also in the area of tailoring the site in terms of design and website operation; for example, site navigation. Furthermore, these findings suggest that involving stakeholders in the development process facilitated buy-in and ultimate acceptance of this new tool.

The current study strategy parallels the model proposed by Street (2003) for IHCs and cancer care. Stage 1 focuses upon the interaction between institutions, consumers, and technology. The current study of the website adaptation process using nominal group technique described the dynamics of this stage. Stage 2 focuses upon the interplay of user, media, and message characteristics and resulting perceptions of the value of using the media for health resources. The current evaluation study addresses this latter element of Stage 2. Stage 3 addresses health behaviors and longer term outcomes. Evaluation data in Stage 3 substance abuse or health IHCs are sparse indeed and should be a focus of future studies. One hint at the potential for demonstrating positive end-user outcomes is E.T. Miller's (2001) dissertation that showed the value of IHC regarding alcohol skills training in college students.

The retrospective pretest-posttest design of this evaluation reduces response shift bias, which occurs when the knowledge acquired during the intervention being evaluated alters (shifts) the internal metric by which a respondent rates their behaviors (Howard, Schmeck, \& Bray, 1979). Therefore, due to response shift bias, the postintervention response is no longer comparable to the pre-intervention response. The retrospective pretest-posttest design reduces this bias by taking pre- and post-intervention measures at the same time (post-intervention). However, some shift bias could still exist and it is unclear to what extent in this study.

Retrospective pretests are no more susceptible than traditional pretest and posttest designs to social desirability or impression management bias (Howard, Millham, Slaten, \& O'Donnell, 1981). Furthermore, the retrospective nature of the approach is well suited to circumstances like this study where formal pretests were not feasible (Pratt et al., 2001).

\section{Limitations}

When interpreting the findings of this study, several limitations should be taken into consideration. The quantitative website user data collection by SAMHSA did not include details about the characteristics and demographics of OTRT users. Though the numbers suggest that OTRT was consistently being used it is not possible to determine how heavily or whether users were from the target audience (Operation RedBlock team volunteers and captains). However, the nearly constant levels of unique and multiple visitors is consistent with a small cadre of steady users, as would be expected if OTRT became a valuable tool for Operation RedBlock captains and team members and Amtrak managers.

While the retrospective pretest posttest design minimizes response shift bias, it may be susceptible to recall bias where recall pretest is less reliable than posttest because of the greater amount of time that has passed since the pretest period.

There is little information on the characteristics and demographics of questionnaire respondents. Questionnaires were collected for all six operational divisions. However, it is not known if the questionnaire respondents are representative of Operation RedBlock teams.

The study design lacks a control group that allows OTRT users could not be compared to non-users. Therefore, we could not control for factors other than OTRT that may correspond to the outcome (facilitation of peer activities in preventing substance abuse). These factors might include general trends and factors that influence information availability and retrieval.

It is not known if these findings are generalizable to other workplaces or industries. They may only be generalizable to workplaces similar to Amtrak: transportation, a strong unionized workforce, and a culture that protects and values confidentiality. 


\section{Conclusion}

The current evaluation demonstrates that customized internet-based interactive health communications can increase the ability of peer helpers to operate a substance abuse prevention and early intervention program. Miller, Zaloshnja, and Spicer (2007) demonstrated that the Operation RedBlock approach reduces injuries and offers an employer a return on investment. Increasing the effectiveness of the Operation RedBlock teams should enhance these effects. Future research should explore the impact of the OTRT enhancement of Operation RedBlock including outcomes such as outreach, treatment-seeking, improved workplace performance and safety, and cost-effectiveness.

\section{Acknowledgment}

We thank Christopher Ringwalt who reviewed an earlier version of this manuscript. This study was funded by contracts 277-00-6103 and GS-106-0267K, task Order 277-05-0103 with the U.S. Center for Substance Abuse Prevention. All views expressed herein and any errors or omissions are those of the authors and may not reflect those of the U.S. Center for Substance Abuse Prevention.

\section{References}

Bacharach, S. B., Bamberger, P. A., \& Sonnenstuhl, W. J. (1996). Labor-based peer assistance in the workplace. Industrial Relations, 35(2), 261-275.

Baker, L., Wagner, T. H., Singer, S., \& Bundorf, M. K. (2003). Use of the Internet and e-mail for health care information: Results from a national survey. Journal of the American Medical Association, 289(18), 2400-2406.

Bonferroni, C. E. (1935). Il calcolo delle assicurazioni su gruppi di teste, Studi in Onore del Professore Ortu Carbonia (pp. 13-60). Rome, Italy.

Bonferroni, C. E. (1936). Teoria statistica delle classi e calcolo delle probabilità, Pubblicazioni del R Istituto Superiore di Science Economiche e Commerciali di Firenze (Vol. 8, pp. 3-62). Rome, Italy.

Casebeer, L. L., Strasser, S. M., Spettell, C. M., Wall, T. C., Weissman, N., Ray, M. N., \& Allison, J. J. (2003). Designing tailored Web-based instruction to improve practicing physicians' preventive practices. Journal of Medical Internet Research, 5(3), e20.

Center for Substance Abuse Prevention. (2003). GetFit.SAMHSA.Gov: Online workplace health promotion, intervention, and prevention. Substance Abuse and Mental Health Services Administration, U.S. Department of Health and Human Services. Accessed January, 2003, from the World Wide Web: http://getfit.samhsa.gov/default.aspx

Copeland, J., \& Martin, G. (2004). Web-based interventions for substance use disorders: A qualitative review. Journal of Substance Abuse and Treatment, 26(2), 109-116.

Creswell, J. W. (2003). Research design: Qualitative, quantitative and mixed methods approach. (2nd ed.). Thousand Oaks, CA: Sage Publications.

Delbecq, A. L., Van de Ven, A. H., \& Gustafson, D. H. (1975). Group techniques for program planning: A guide to nominal group and Delphi processes. Glenville, IL: Scott-Foresman \& Co.

Doumas, D. M., McKinley, L. L., \& Book, P. (2009). Evaluation of two Web-based alcohol interventions for mandated college students. Journal of Substance Abuse Treatment, 36(1), 65-74.

Galvin, D. M. (2003, November). Interactive health communications and employee assistance programs: What we have learned. Paper presented at the Employee Assistance Professionals Association, Professional Development Institute, November 21, 2003., New Orleans, LA.

Howard, G. S., Millham, J., Slaten, S., \& O'Donnell, L. (1981). Influence of subject response style effects on retrospective measures. Applied Psychological Measurement, 5(1), 89-100.

Howard, G. S., Schmeck, R. R., \& Bray, J. H. (1979). Internal validity in studies employing self-report instruments: A suggested remedy. Journal of Educational Measurement, 10, 305-315. 
Kessler, R., Mickelson, K., \& Zhao, S. (1997). Patterns and correlates of self-help group membership in the United States. Social Policy, 27, 27-46.

Larson, S.L., Eyerman, J., Foster, M.S., \& Gfroerer J.C. (2007). Worker substance use and workplace policies and programs. Rockville, MD.: Department of Health and Human Services, Substance Abuse and Mental Health Services Administration, Office of Applied Studies. Retrieved from http://purl.access.gpo.gov/GPO/LPS84606.

Linke, S., Murray, E., Butler, C., \& Wallace, P. (2007). Internet-based interactive health intervention for the promotion of sensible drinking: Patterns of use and potential impact on members of the general public. Journal of Medical Internet Research, 9(2), e10.

Matano, R. A., Koopman, C., Wanat, S. F., Winzelberg, A. J., Whitsell, S. D., Westrup, D., Futa, K., et al.. (2007). A pilot study of an interactive website in the workplace for reducing alcohol consumption. Journal of Substance Abuse Treatment, 32(1), 71-80.

Matano, R. R., Futa, K. T., Wanat, S. F., Mussman, L. M., \& Leung, C. W. (2000). The employee stress and alcohol project: The development of a computer-based alcohol abuse prevention program for employees. Journal of Behavioral Health Services and Research, 27(2), 152-165.

Miller, E. T. (2001). Preventing alcohol abuse and alcohol-related negative consequences among freshmen college students: Using emerging computer technology to deliver and evaluate the effectiveness of brief intervention efforts. Dissertation Abstracts International Section B: The Sciences and Engineering, 61(8-B).

Miller, T. R., Zaloshnja, E., \& Spicer, R. S. (2007). Effectiveness and benefit-cost ratios of peer-based workplace substance abuse prevention coupled with random testing. Accident Analysis and Prevention, 39(3), 565-573.

Noah, S. A., Abdullah, S. N., Shahar, S., Abdul-Hamid, H., Khairudin, N., Yussof, M., Ghazali, R., Mohd-Yusoff, N., Shafii, N. S., \& Abdul-Manaf, Z. (2004). DietPal: A Web-Based Dietary Menu-Generating and Management System. Journal of Medical Internet Research, 6(1), e4.

Normand, J., Lempert, R., \& O’Brien, C. 1994. Under the influence? Drugs and the American workforce. Washington, DC: National Academy Press, IOM (Institute of Medicine).

Pratt, C. C., McGuigan, W. C., \& Katzev, A. R. (2001). Measuring program outcomes: Using retrospective pretest methodology. American Journal of Evaluation, 21(3), 341-349.

Robinson, T. N., Patrick, K., Eng, T. R., \& Gustafson, D. (1998). An evidence-based approach to interactive health communication. Journal of the American Medical Association, 280(14), 12641269.

SAS Institute Inc. (1999). The SAS System for Windows, Release 8. Cary, NC: SAS Institute Inc.

Science Panel on Interactive Communication and Health. (1999). Wired for health and well-being: The emergence of interactive health communication. (T. R. Eng \& D. H. Gustafson (Eds.)). Washington, DC: US Department of Health and Human Services, U.S. Government Printing Office.

Siegel, S., \& Castellan Jr., N. J. (1988). Nonparametric statistics for the behavioral sciences. (2nd ed.). New York, NY: McGraw Hill, Inc.

Spicer, R.S., Miller, T.R. (2005). The impact of a workplace peer-focused substance abuse prevention and early intervention program. Alcoholism: Clinical and Experimental Research, 29(4):609-611.

Street, R. L., Jr. (2003). Mediated consumer-provider communication in cancer care: The emerging potential of new technologies. Patient Education and Counseling, 50, 99-104.

Substance Abuse and Mental Health Services Administration (2009). Results from the 2008 National Survey on Drug Use and Health: National Findings (Office of Applied Studies, NSDUH Series H-36, HHS Publication No. SMA 09-4434). Rockville, MD.

United States Census Bureau (2012a). Statistical abstract of the United States: 2012. Washington, DC: U.S. Government Printing Office, table 1158. Retrieved from http://www.census.gov/compendia/statab/2012/tables/12s1158.pdf. 
United States Census Bureau (2012b). Statistical abstract of the United States: 2012. Washington, DC: U.S. Government Printing Office, table 1159. Retrieved from http://www.census.gov/compendia/statab/2012/tables/12s1159.pdf.

United Transportation Union, \& The Brotherhood of Locomotive Engineers. (2000). Operation REDBLOCK. United Transportation Union. Accessed January, 2003, from the World Wide Web: http://www.utu.org/DEPTS/PR-DEPT/REDBLOCK.HTM

Walters, S. T., Miller, E., \& Chiauzzi, E. (2005). Wired for wellness: E-interventions for addressing college drinking. Journal of Substance Abuse Treatment, 29(2), 139-145.

Weisner, C., Greenfield, T., \& Room, R. (1995). Trends in the treatment of alcohol problems in the U.S. general population. American Journal of Public Health, 85, 55-60.

Winzelberg, A., \& Humphreys, K. (1999). Should patients' religiosity influence clinicians' referral to $12-$ step self-help groups? Evidence from a study of 3,018 male substance abuse patients. Journal of Counseling and Clinical Psychology, 67(5), 790-794.

Author Information

Deborah M. Galvin, $\mathrm{PhD}$

1Substance Abuse and Mental Health Services Administration,

Center for Substance Abuse Prevention

Rockville, MD 20857

Rebecca S. Spicer, $\mathrm{PhD}^{*}$

Pacific Institute for Research and Evaluation

11720 Beltsville Drive, Suite 900

Beltsville, MD 20705

Phone: 301-755-2732

Fax: 301-755-2799

Email: spicer@pire.org

Les R. Becker, $\mathrm{PhD}$

${ }^{2}$ Pacific Institute for Research and Evaluation 11720 Beltsville Drive, Suite 900

Beltsville, MD 20705

Ted R. Miller, $\mathrm{PhD}$

${ }^{2}$ Pacific Institute for Research and Evaluation 11720 Beltsville Drive, Suite 900

Beltsville, MD 20705

Dexter M. Taylor, $\mathrm{PhD}$

Pacific Institute for Research and Evaluation 11720 Beltsville Drive, Suite 900

Beltsville, MD 20705

Julie A. Sabol

ORC Macro

11785 Beltsville Drive

Beltsville, MD 20705

* corresponding author 